\title{
The Relationship between Fathers' Parenting Attitudes and Their Child's Emotional Competence for Taiwan Example
}

\author{
Ching-Sheue $\mathrm{FU}^{1} \bowtie$ \\ Jia-Yi GAO \\ ${ }^{1,2}$ Department of Early Childhood Caring and Education, Chung Hwa University of Medical Technology, \\ Taiwan \\ Email:misssallyfu@gmail.com
}

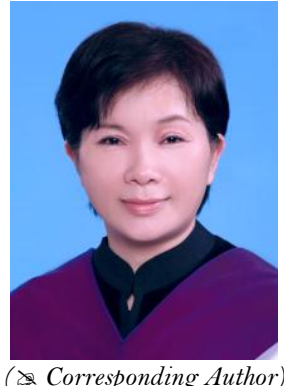

Corresponding Author)

\begin{abstract}
Children's emotional competence development is mainly influenced by their caretakers. The old days when mothers were the main caretakers of their children have passed. There have been more and more fathers taking care of their children personally. This study aims to explore the relationship between fathers' parenting attitudes and their child's emotional competence. A survey was conducted with the "Fathers' Parenting Attitudes Scale" and the "Children's Emotional Competence Scale", with the subjects being the children from the preschools in Taiwan and their father selected using the snowball sampling method. The result shows that the relationships between fathers' parenting attitudes and various aspects of children's emotional competence are all not significant. It seems that the traditional Chinese concept of "fathers being stern and mothers being benevolent" still remains nowadays.
\end{abstract}

Keywords: Fathers' parenting attitudes, Child's emotional competence, Pre-School.

Citation | Ching-Sheue FU; Jia-Yi GAO (2017). The Relationship between Fathers' Parenting Attitudes and Their Child's Emotional Competence for Taiwan Example. Asian Journal of Education and Training, 3(2): 118-123.

History:

Received: 15 August 2017

Revised: 29 November 2017

Accepted: 4 December 2017

Published: 6 December 2017

Licensed: This work is licensed under a Creative Commons

Attribution 30 License (c)

Publisher:Asian Online Journal Publishing Group
Contribution/Acknowledgement: Both authors contributed to the conception and design of the study.

Funding: This research was supported from Ministry of Science and Technology, R.O.C. (No. 104-2815-C-273-001-H)

Competing Interests: The authors declare that they have no conflict of interests.

Transparency: The authors confirm that the manuscript is an honest, accurate, and transparent account of the study was reported; that no vital features of the study have been omitted; and that any discrepancies from the study as planned have been explained.

Ethical: This study follows all ethical practices during writing.

\section{Contents}

1. Introduction

2. Literature Review

3. Methods

4. Results

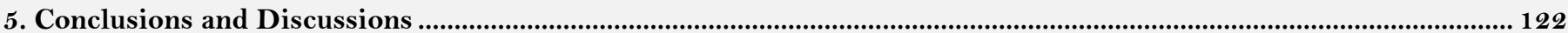

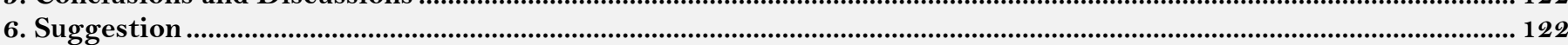

References. 


\section{Introduction}

Since a child is born, he begins to contact the surrounding physical, psychological, and social environments. In the course of interactions, he would develop his unique personality traits. A family is essential in a child's growing years. It is his source of emotional support, as well as his first place to learn to be aware of his own emotions (Moll et al., 1992; Bronfenbrenner, 2005). Thus, parents' parenting attitudes are important to not only enlightening their child in self-learning of emotion management but also reducing their sense of unhappiness so that they can grow up happily (Hung, 2007).

In 2015, there were 14,258 fathers applying for parental leave without pay of Taiwan. The number is doubled compared to the previous year (Ministry of Labor, 2016). In Taiwan, the percentage of fathers willing to stay home taking care of their child is higher than other nearby countries such as Japan and Korea. The traditional concept of "husbands taking charge of external matters and wives domestic matters" is now being overturned in Taiwan. The traditional concept of "the father being to blame for his child's faults" shows the importance of the role a father plays in his child's growing years. According to the old concept, a father is responsible for his child's deviant behaviors. In preschools, interactions between teachers and parents are mostly interactions between teachers and mothers. With the change of time, has fathers' parenting changed in Taiwan? Chien (1996) suggested that parents' parenting methods have been changing gradually in Taiwan. In the past, mothers played the role of the benevolent parent while fathers played the role of the stern parent. Now, mothers discipline their child sternly and play the role of the main executioner for parenting, while fathers play the role of the coordinator, a buffering role of care. Under the influences of changing social trends and values, fathers in Taiwan indeed choose a different way of parenting nowadays. Goleman (1995) believed that parents' emotional reactions would influence their parenting, resulting in emotional social behaviors. Children get to know this world through observation. Every day they learn experiences in relation to emotions from their parents' behaviors. Children's behaviors lead to their parents' reactions, and parents parenting behaviors also lead to children's various emotions. From these interactions, children learn knowledge and experiences regarding expressions of emotions, how to react to others' positive/negative emotions, and which emotions may arise in which situations. Thus, in Taiwan, fathers begin to participate in parenting their child. The purpose of this study is to explore the relationship between their parenting attitudes and their child's emotional competence, in hopes of providing suggestions to adjust family parenting and to improve children's emotional competence.

\section{Literature Review}

\subsection{Fathers' Parenting Attitudes}

Parents' "parenting attitudes" cover their knowing (knowledge or faith), feelings (emotions), and behavioral intentions (tendencies) while instructing or teaching their child (Yang, 1986) as well as how they educate and nurture their child regarding their child's attitudes, feelings, hopes, thoughts, knowledge, hobbies, values, behaviors, and personal qualities (Yang, 2006). Yang (2007) suggested that parents' "parenting attitudes” are their views and methods regarding daily events in education and parenting, in other words, the attitudes they hold while parenting their child. Chang (2009) explained with the internal and external aspects. The internal aspect is the "attitude" aspect, while the external aspect is the "action" aspect. Parents' internal attitudes and values may influence their behaviors of nurturing their child.

Based on the scholars' opinions above, this study considers fathers' parenting attitudes as including fathers' knowledge, faith, feelings, values, and behaviors while teaching and rearing their child.

There are different ways to interpret parenting attitudes based on different research views, including the single-dimension, two-dimension, and multi-dimension views (Baumrind, 1991).

\subsubsection{The Single-Dimension View}

The single-dimension view divides parenting attitudes distinctly into various types based on their presentation. These types are independent without overlapping. Baumrind (1970) believed that parents' parenting attitudes are influenced by just one dimension, their tendency toward authority. Based on the degree of control, parents' parenting attitudes can be classified into "tolerant type", "authoritative and autocratic type", and "authoritative and open-minded type".

\subsubsection{The Two-Dimension View}

The two-dimension view classifies parenting attitudes in a two-dimension way using two features used to describe parenting behaviors. Sometimes, combinations of two different features are used. Sometimes, each feature is divided into high and low dimensions. The advantage of this classification method is that it is more practical than the multi-dimension classification method (Lin, 2008). Maccoby and Martin (1983) classified parents' parenting attitudes based on two dimensions, "demands" and "responses". They believed further dividing each of these two dimensions into high and low dimensions to create four categories can better interpret how parents nurture their child. "Demands" are related to the standards and requirements parents determined for their child. Demands imply orders or threats and punishments which rules are not followed. "Responses" are parents' responses to their child, including offering consistent care and love.

\subsubsection{The Multi-Dimension View}

The multi-dimension view further includes parents' own emotional states to create a three-dimensional space for classification of parenting methods. It is the most complete classification method. However, due to its complexity, it is rarely used by scholars. To classify parenting attitudes, the single-dimension view is too simple and the multi-dimension view is rather complex, so this study adopts the two-dimension view with two dimensions, “demands" and "responses”, to interpret fathers' parenting attitudes. 


\subsection{Children's Emotional Competence}

The basis of emotional competence is emotional intelligence. This competence is obtained through learning. It helps to achieve outstanding work performances. Also, it expands the fundamental competence structure of emotional intelligence to cover managing one's own "individual competence" and dealing with others' "social competence”. Individual competence includes competence of three aspects, self awareness, self regulation and discipline, and facilitating goal achievement. Social competence includes competence of two aspects, empathy and social skills (Goleman, 1995).

Since birth, a baby can show reflex facial expressions, such as happiness, sadness, anger, and surprise. When he is about 3 weeks old, he develops social smiles. When he is about four months old, he can show facial expressions of surprise and anger. When he is about one year old, he can show fear and shy through facial expressions as well. When he is nine to fourteen months old, he gets angry more frequently. After he is one year old, emotions such as hostility and envy begin to appear. When he is two to four years old, he can express pride, shame, embarrassment, disdainfulness, and guilt through facial expressions (Izard and Malatesta, 1987; Camras, 1988; Malatesta, 1988). Thus, emotional competence is developed through a certain process.

Hyson (2004) proposed three main features of children's emotions: 1) Children's degrees of emotional responses may decrease as they grow up. 2) Children can gradually transform their emotional responses so that these responses can be approved by the society. 3) Through trainings and social pressure, some obvious emotional responses can be gradually improved. Hyson suggested that children of different ages have different emotion developments, which can be discussed from five aspects, emotion expression, emotion regulation, emotion comprehension, response to others' emotion, and emotional attachment.

The plan for preschool education courses in Taiwan includes "emotions" in the learning fields. The idea of course design is to, through an organized and consistent course design, develop children's four major emotional competence, including "awareness and identification", “comprehension”, "expression”, and "regulation” in the "emotional areas".

Children's emotional competence is developed in an early stage. A child is capable of perceive and identify his own emotions when he is about eighteen months old. When he is about four years old, he can identify others' emotions (Carroll and Steward, 1984; Lewis, 1990). At the age of two, he can describe the cause of an event using complex sentences (Carroll and Steward, 1984; Brown and Dunn, 1996). At the age of three, he can interpret others' behaviors based on his own beliefs (Carroll and Steward, 1984; Brown and Dunn, 1996). As he is four to six years old, he can detect effective emotion regulation strategies (Brown et al., 1991; Brenner and Salovey, 1997). The first competence children develop is the competence of awareness and identification, followed by the competence of emotion expression and emotion comprehension, and lastly emotion regulation. Thus, as children grow up, external stimulations have gradually become catalysts to develop their emotional competence. When their father's parenting methods become an external stimulation factor, their emotional competence may be developed in different aspects.

\section{Methods}

\subsection{Participants}

The research participants were selected using the snowball sampling method. A child was qualified only when his father and preschool teacher both agreed to participate. A total of 326 questionnaires were issued, and 282 were retrieved. The response rate is $86 \%$. 9 of the retrieved questionnaires are invalid. Thus the number of valid questionnaires is 273 . The idea of the snowball sampling method is to find other research subjects based on a small group of people. First, a small group of people are selected from the population. Then, these people are requested to introduce other people they know from the population (Wang and Wang, 2010).

\subsection{Research Tools}

The research tools used by this study include the "Fathers' Parenting Attitudes Scale" and "Children's Emotional Competence Scale". The data collected using the "Fathers' Parenting Attitudes Scale" (Li, 2008) were analyzed using the factor analysis method. Two factors were obtained, "responses" and "demands". These two factors can explain $28.62 \%$ and $16.80 \%$ of the total variation, respectively. The accumulated total variation explained is $45.42 \%$. The Cronbach's $\alpha$ value of the overall questionnaire is .92. The Cronbach's $\alpha$ value of the "responses subscale" is .91 and that of the "demands subscale" is .81. The accumulated total variation explained by the subscales is $57.70 \%$. The validity and reliability of the questionnaire are both very good. This scale is applicable to evaluations of preschool children's father's parenting attitudes. The Likert-type 6-point scale was adopted for measurement. The scoring method is as follows: 6 points for "strongly agree", 5 points for "agree", 4 points for "slightly agree", 3 points for "slightly disagree", 2 points for "disagree", and 1 point for "strongly disagree".

The "Children's Emotional Competence Scale" used in this study is the " 3 to 6 year-old children's emotional competence development scale" designed by Chien and Kuo (2006) based on the "6-year old children's emotional competence development scale" (Hsing and Chien, 2004) and domestic and foreign literature regarding children's emotional competence, with the processes of questionnaire item pre-tests and analyses. The scale used by this study is for children aged 3 to 6 years. The Cronbach's $\alpha$ value of the overall questionnaire is .97 , and those of the subscales are between .76 and .97. The definition of "emotional competence for the "Children's Emotional Competence Scale" is the competence children need when facing an emotional situation, including four competence: competence of emotional awareness and identification, competence of emotion comprehension, competence of emotion expression, and competence of emotion regulation.

The "Children's Emotional Competence Scale" questionnaires were issued to preschool teachers who had spent at least 3 hours with the participating children and already observed the children's emotional behaviors for at least three successive months. The answering the questionnaire, they were asked to check the options based on the frequencies of the children's behaviors in the 3 recent months. The scoring method is as below: 1 point for "the child has never done this before", 2 points for "the child does it when being reminded", 3 points for "the child 
sometimes does it, sometimes does it when being reminded", 4 points for "the child does it on his own", and also 1 point for "this behavior has never been observed", as the child may have already developed the competence but his teacher hasn't observed it yet. A higher score means better emotional competence, while a lower one means worse emotional competence.

\section{Results}

\subsection{The Current Status of Fathers' Parenting Attitudes}

A total of 273 fathers participated in this study. Their average score for the "Fathers' Parenting Attitudes Scale" is 3.52 points, which is between "slightly agree" and "slightly disagree" on the 6-point scale, with the standard deviation being .016. As for the two aspects of parenting attitudes, the average score for "demands" is 3.84, points, slightly higher than the average score for "responses", 3.19 points. This means that more focus is placed on the demands aspect in fathers' parenting attitudes, as shown in Table 1.

\begin{tabular}{l|l|l|l}
\multicolumn{4}{c}{ Table-1. The Descriptive Statistics of the Factors of Fathers' Parenting Attitudes } \\
\hline Item & $\boldsymbol{n}$ & Mean, $\boldsymbol{M}$ & Standard Deviation, $\boldsymbol{S D}$ \\
\hline Responses & 273 & 3.19 & .017 \\
\hline Demands & 273 & 3.84 & .014 \\
\hline Total & 273 & 3.52 & .016 \\
\hline O= strongly disagree 6=very agree
\end{tabular}

Based on the study by Baumrind (1991) this study used two dimensions, "demands" and "responses", for parenting attitudes. The result of this study shows that the fathers' parenting attitudes focus more on the "demands" aspect. That is, the fathers would establish some rules for their child to follow. Their parenting methods are rather harsh and strict. The score of "responses" is lower than that of "demands". In other words, there are fewer loving fathers than stern father. And the score of "demands" is almost 4 points. It is clear that there are more fathers whose parenting attitudes are rather harsh.

Generally speaking, the responses and demands factors of the subjects' fathers' patenting attitudes are not very different. Both scores are slightly higher than the means on the 6-point scale. Apparently, the fathers' patenting attitudes are with a lot of responses and high demands. Baumrind (1991) believed this is the best type of parenting attitudes. The result shows that the fathers' patenting attitudes are consistent with social expectations. They can judge a matter as it stands when it comes to teaching their child, and respond with love and support.

\subsection{The Current Status of Children's Emotional Competence}

A total of 273 children participated in this study. The result shows that the children's average score of the "Children's Emotional Competence Scale" is 3.27, with the standard deviation being .038. Regarding the four emotion aspects, the performance of "emotion awareness and identification, EAI" $(\mathrm{M}=3.44, \mathrm{SD}=.032)$ is the best, followed by "emotion expression, $\mathrm{EE}$ " ( $\mathrm{M}=3.28, \mathrm{SD}=.036)$, "emotion comprehension, $\mathrm{EC}$ " $\mathrm{M}=3.21, \mathrm{SD}=.043)$, and lastly "emotion regulation, ER" ( $\mathrm{M}=3.16, \mathrm{SD}=.040)$. Generally speaking, the children's emotional competence score is over 3 points, close to 4 on the 4-point scale, meaning that the children's emotional competence is quite good, as shown in Table 2.

Table-2. The Statistics for the Factors of Children's Emotional Competence

\begin{tabular}{l|l|l|l}
\hline Item & $\boldsymbol{n}$ & Mean, $\boldsymbol{M}$ & Standard Deviation, $\boldsymbol{S D}$ \\
\hline EAI & 273 & 3.44 & .032 \\
\hline EE & 273 & 3.28 & .036 \\
\hline EC & 273 & 3.21 & .043 \\
\hline ER & 273 & 3.16 & .040 \\
\hline Total & 273 & 3.27 & .038 \\
\hline O= strongly disagree 6=very agree
\end{tabular}

The data obtained from the children's preschool teachers show that the children's emotional competence is moderate or good. The score of the "emotional awareness and identification, EAI" competence is close to 4 points, the perfect score. This shows that the "emotional awareness and identification, EAI" competence of the children participating in this study is very good. Furthermore, among the 4 factors, the score of the "emotion regulation, ER" competence is the lowest. Yet, the score is still higher than 3 points. This means the children's "emotion regulation, ER" competence is still quite good.

\subsection{The Analyses Regarding Fathers' Patenting Attitudes and Children's Emotional Competence}

According to the correlation matrices of the 2 factors of fathers' patenting attitudes, "responses" and "demands". The 4 factors of children's emotion competence, "emotional awareness and identification, EAI", "emotion comprehension, EC", "emotion expression, EE", and "emotion regulation, ER", the relationship between "fathers' patenting attitudes" and "children's emotion competence" is not significant. This implies that fathers' patenting attitudes have nothing to do with their child's emotion competence, as shown in Table 3 below.

Table-3. The Correlation Coefficients of the Factors of Fathers' Patenting Attitudes and Children's Emotion Competence

\begin{tabular}{l|l|l|l|l|l|l}
\hline Variable & demands & responses & EAI & EC & EE & ER \\
\hline demands & 1 & & & & & \\
\hline responses & $.183^{* *}$ & 1 & & & & \\
\hline EAI & -0.007 & 0.025 & 1 & & & \\
\hline EC & 0.037 & 0.019 & $.740^{* *}$ & 1 & & \\
\hline EE & 0.039 & -0.003 & $.632^{* *}$ & $.806^{* *}$ & 1 & \\
\hline ER & 0.058 & 0.005 & $.507^{* *}$ & $.670^{* *}$ & $.656^{* *}$ & 1 \\
\hline
\end{tabular}


According to previous studies, when their parents adopt the "authoritative and open-minded" patenting method, children's "emotional awareness and identification, EAI", "emotion expression, EE", and "emotion regulation, ER" competence can be positively influenced. If their parents adopt the "ignoring and indifferent" parenting method, their emotional competence it would be rather disadvantageous for the development of their emotional competence (Hsiao, 2002). Lin (2010) found that, for retarded children, all the aspects of their emotional competence are significantly related to their parents' "democratic and imposing" parenting attitude. Liu (2009) found that the "responses" aspect of parenting attitudes is significantly and positively related to the "emotional awareness and identification, EAI" and "emotion expression, EE" aspects of children's emotional competence, while the "demands" aspect of parenting attitudes is significantly and negatively related to the "emotion regulation" aspects of children's emotional competence. However, this study focus on fathers' parenting attitudes and the result shows that fathers' parenting attitudes have nothing to do with their child's emotional competence. Although nowadays fathers often play the important role of caretaker, their parenting attitudes are not related to their child's emotions. They may not be as good as mothers when playing the role of caretaker.

\section{Conclusions and Discussions}

\subsection{The Focus of Fathers' Parenting Attitudes is Mostly on the "Demands" Aspect}

The result of this study shows that the focus of fathers' parenting attitudes is mostly on the "demands" aspect. In other words, fathers usually provide their child some standard rules for behaviors. If their child disobeys their rules, punishment will be imposed or the child's behaviors will be strictly regulated. This phenomenon is related to the traditional Chinese concept that "a father shall be held responsible for nurturing his child." Fathers often treat their child strictly when it comes to nurturing. Their purpose is to make sure their child being on the right track following conventional practices.

\subsection{Children's “Emotion Regulation” Competence Can be Further Developed}

The result of this study shows that among four aspects of children's emotional competence, namely "emotional awareness and identification, EAI", "emotion comprehension, EC", "emotion expression, EE", and "emotion regulation, ER", the score of emotional awareness and identification is the highest. And there is still room for development of emotion regulation competence. Thus, during the preschool years, although children can understand what causes their emotions, there are not good at emotion regulation. As a result, they just get angry or laugh whenever they want. This finding is consistent with Wang (2009). Wang suggested that emotions are presented through not only facial expressions and apparent feelings, but also some internal ways. It is very common in a preschool to see a sleepy child brought to the school by his parents and gets angry or emotional or cries very easily as he still wants to sleep. It is very likely that this child's needs are not satisfied. And since he is not yet socialized, he doesn't think that he should hide this emotion (Wang, 2009). Bad emotion regulation competence may influence a child's social development.

\subsection{There are Still Questions Regarding the Finding that Fathers' Parenting Attitudes are Not Related to their Child's Emotional Competence}

It's more and more common to see fathers taking care of their child and picking up and dropping off their child at preschool. However, the result of this study shows that even though fathers, who are responsible for the income of their family, have gradually become a caretaker as well, their parenting attitudes still have no influence on the development of their child's emotional competence. The traditional concept that "a father should be stern while a mother should be benevolent" doesn't seem to be different nowadays. Does this mean fathers only involve in parenting in the aspect of daily care, not in the aspect of nurturing? Further research is required to clarify fathers' role during their child's growth process.

\section{Suggestion}

The research subjects of this study are children's father and preschool teacher. The questionnaires were filled by them. And this study did not find any evidence proving the relationship between fathers' parenting attitudes and their child's emotional competence. If the questionnaire about children's emotional competence could be filled by their father, the research finding might have been different. After all, a child's father and his preschool teacher may interpret his emotional competence differently. It is suggested that in the future this questionnaire can be filled by fathers in order to more clearly explore the aspects of their child's emotional competence development.

\section{References}

Baumrind, D., 1970. Socialization and instrumental competence in young children. Young Children, 26(2): 104-1 19. View at Google Scholar

Baumrind, D., 1991. The influence of parenting style on adolescent competence and substance use. Journal of Early Adolescence, 11(1): 5695. View at Google Scholar | View at Publisher

Brenner, E.M. and P. Salovey, 1997. Emotion regulation during childhood: Development, interpersonal, and individual considera tions. In P. Salovey, \& D. Sluyter (Eds.), Emotional development and emotional Intelligence: Implication for educators. New York: Basic Books. pp: 168-192.

Bronfenbrenner, U., 2005. Making human beings human: Bioecological perspectives on human. Thousand Oaks, CA: Sage.

Brown, J.R. and J. Dunn, 1996. Continuities in emotion understanding from three to six years. Child Development, 67(3): 789-802. View at Google Scholar | View at Publisher

Brown, K., K. Covell and R. Abramovitch, 1991. Lottery winners and accident victims: Age differences in understanding and recognition. Merrill- Palmer Quarterly, 37: 273-287. View at Google Scholar

Camras, L.A., 1988. Darwin revisited: An infant's first emotional facial expressions. In H. Oster (Chair), Emotional expressions in infants: New perspectives on an old controversy. Washington, DC: International Conference on Infant Studies.

Carroll, J.J. and M.S. Steward, 1984. The role of cognitive development in children's understanding of their own feelings. Child Development, 55(4): 1486-1492. View at Google Scholar | View at Publisher

Chang, M.C., 2009. The relationship among parental raising attitude, intrapersonal intelligence ad interpersonal intelligence between students from a single-child family and a multiple-children family. Master's Dissertation, Graduate Institute of Psychology and Counseling, University of Taipei, Unpublished. Taipei City. 
Chien, C.C., 1996. A study of important factors effective parental child-rearing practices-through ecological systems theory. Taipei: National Taiwan Normal University.

Chien, S.C. and L.T.W. Kuo, 2006. Educare activity guidelines and competence indicators for preschools after the integration of kindergartens and nursery schools. The Report of the Emotion Field Research Team. Project Research Report Commissioned by the Ministry of Education.

Goleman, D., 1995. Emotional intelligence. New Book: Bantam Books.

Hsiao, R.L., 2002. A study on the related factors of emotion adjustment among elementary students. Master's Dissertation, Department of Educational Psychology and Counseling, National Pingtung University. Pingtung County.

Hsing, M.L. and S.C. Chien, 2004. A research project of the competence indicators for curriculum guidelines for national education nursery classes. Taipei City: National Education Department, Ministry of Education.

Hung, S.M., 2007. The study of interpersonal relationship among parenting styles, emotion awareness ability and self-concept of the high grade elementary school students. Master's Dissertation, Tainan University of Technology. Taipei.

Hyson, M.C., 2004. The emotional development of young children: Building an emotion-centered curriculum. 2nd Edn., New York: Teachers College Press.

Izard, C.E. and C. Malatesta, 1987. Perspectives on emotional development: Differential emotions theory of early emotional development. In J. D. Osofsky (Ed.), Handbook of infant development (2nd Edn.,). New York: Wiley. pp: 494-554.

Lewis, M., 1990. Self-knowledge and social development in early life. In A. P. Lawrence (Ed.), Handbook of personality: Theory and research. New York: Guilford. pp: 277-300.

Li, Y.F., 2008. Relative research in paternal attitude toward the parenting and children's social behavior. Master's Disserta tion, Graduate Institute of Early Childhood Education, National Taitung University. Taitung County.

Lin, C.F., 2008. A study of the roles of the perception of parenting style of academic failure and parenting attributions on academic selfesteem and parent-child relationship of junior high school students. Master's Dissertation, Graduate Institute of Guidance \& Counseling, National Changhua University of Education, unpublished. Changhua.

Lin, F.C., 2010. A study on relationship between emotional competence of children with developmental delay and parent's nurturing attitude. Master's Dissertation, Graduate Institute of Infant and Child Care, National Taipei University of Nursing and Health Sciences, Unpublished. Taipei City.

Liu, Y.F., 2009. A correlation study between the mother's parenting attitude and the emotional competence of young children: Using Keelung City as an example. Master's Dissertation, Department of Early Childhood Education, National Taitung University. Taitung County.

Maccoby, E.E. and J.A. Martin, 1983. Socialization in the context of family: Parent-child interaction. In E. M. Hetherington (Ed.). Handbook of child psychology: Socialization, personality and social development. New York: Wiley, 4: 1-122.

Malatesta, C.Z., 1988. The role of emotions in the development and organization of personality. In R.A. Thompson (Ed.), Socio emotional development. Lincoln: University of Nebraska Press. pp: 1-56.

Ministry of Labor, 2016. Condition of payment approval of subsidies for parental leave without pay. Retrieved from http://statdb.mol.gov.tw/html/mon/24060.htm [Accessed 2016/10/10].

Moll, L., C. Amanti, D. Neff and N. Gonzalez, 1992. Funds of knowledge for teaching: Using a qualitative approach to connect homes and classrooms. Theory into Practice, $31(2): 132-141$.

Wang, W.K. and C.H. Wang, 2010. Research methods in education. Taipei City: Wunan.

Wang, Y.H., 2009. The study of young children's ability of behavioral regulation, hiding emotion and peer interaction. Master's Dissertation, Graduate Institute of Early Childhood and Family Education, National Taipei University of Education, Taipei

Yang, C.C., 2007. A study on factors influencing parents' rearing attitudes in central part of Taiwan. Master's Dissertation, Department of Early Childhood Education, National Taichung University of Education, unpublished. Taichung City.

Yang, G.S., 1986. Family factors and children's behaviors. Chinese Journal of Psychology, 1(28): 7-28.

Yang, Y.H., 2006. The impact of parenting on the children's problem solving ability. Master's Dissertation, Department of Education, University of Taipei, Taipei City. 